\title{
Cognitive performance in chronic migraine
}

\section{Desempenho cognitivo na enxaqueca crônica}

Isabel Pavão MARTINS

1 Universidade de Lisboa, Faculty of Medicine, Lisbon, Portugal.

¿Universidade de Lisboa, Institute of Molecular Medicine, Lisbon, Portugal.

${ }^{3}$ Hospital Universitário de Santa Maria, Head of Headache Outpatient Clinic, Consultant Neurologist, Lisbon, Portugal.

Isabel Pavão MARTINS ID https:// orcid.org/0000-0002-9611-7400

Correspondence: Isabel Pavão

Martins; E-mail:ipavaomartins@ gmail.com

Conflict of interest: There is no conflict of interest to declare.

Received on February 20, 2020 Accepted on February 28, 2020

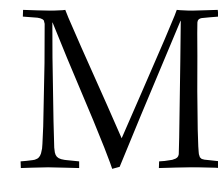

igraine is a ubiquitous disorder that affects $15 \%$ of the world population, particularly women during their most productive years ${ }^{1}$. Migraine produces a variety of symptoms, but its most common presentation consists of recurrent attacks of disabling headaches associated to nausea and intolerance to all sensory stimuli. During attacks, patients often experience cognitive difficulties, with poor ability to concentrate or think clearly, and are unable to deal with multiple tasks ${ }^{2,3}$. The cause of this transient cognitive dysfunction is not known but has been attributed to the complex and widespread brain dysfunction underlying the development of the attacks ${ }^{4,5,6}$, because it cannot be simply explained by pain. In fact, it is not observed in other primary headaches, and the cognitive difficulties are often present during the premonitory and resolution phases of migraine, i.e., both before the onset and after the resolution of pain ${ }^{7,8}$.

The finding of repetitive, transient cognitive dysfunction during migraine attacks raises questions regarding its long-term effects in learning and cognitive development in children with migraine or in later life of adults, especially because migraine has also been related to silent brain lesions, regional atrophy and disorders of brain connectivity ${ }^{9,10}$.

Roughly $2 \%$ of the population and $8 \%$ of subjects with migraine have a severe form of the disorder, called chronic migraine, which is characterized by very frequent attacks that almost merge into each other, often leading to a background of pain with super imposed aggravations $^{11,12}$. Although it is recognized that migraine-related cognitive dysfunction depends on attack frequency ${ }^{13,14}$, it is not known if it reverts between attacks in cases of chronic migraine, with patients experiencing 15 or more days per month with headache, according to the current definition. Moreover, patients with chronic migraine often have medication overuse and many co-morbidities, such as depression, sleep disorders, anxiety and their respective treatment, which may impact cognition.

The article by Latysheva NV et al., published in Arquivos de Neuro-Psiquiatria ${ }^{15}$, adds a relevant piece of information to this topic. The authors performed a neuropsychological evaluation in 144 individuals with chronic migraine (outside acute exacerbations) and compared them to controls with episodic migraine, matched for age, gender and literacy. Individuals with severe depression were excluded, and cognitive performance was controlled for the severity of depressive symptoms and medication overuse. The authors found that subjects with chronic migraine scored below controls in all applied cognitive tests, including attention and processing speed (Digit Symbol Substitution Test), verbal memory (Rey Auditory Verbal Learning Test) and a cognitive screening tool (Montreal Cognitive Assessment). The degree of impairment was not severe, because it did not reach very low scores, but it was consistently low. Moreover, participants with chronic migraine also tend to present more cognitive complaints that those with episodic migraine on a Perceived Deficits Questionnaire. These results thus indicate that chronic migraine is associated to cognitive dysfunction, even between acute attacks, which enlarges the spectrum of difficulties reported by these patients.

Such data have clinical and research implications. First, it means that one must not overlook the cognitive complaints reported by patients with chronic migraine, considering they may correspond to an objective lower cognitive performance. Second, it raises the question of the temporal, and eventually causal, relation between migraine chronification and cognitive dysfunction (which comes before or after) and its long-term outcome, namely its reversibility and impact on age-associated decline. Third, in methodological terms, it means that one needs to separate 
chronic from episodic migraine populations in any cognitive study. In fact, although most studies did not associate episodic migraine with interictal dysfunction ${ }^{16,17}$, one of the studies stating the opposite included $20 \%$ of patients with chronic migraine ${ }^{18}$, which may have introduced a bias in the results.
The current report study does not allow to answer these questions and more studies will be needed.

Finally, the finding of poor cognition in chronic migraine increases the scope of the impact of this disorder and stresses the need to look at migraine as a brain disorder.

\section{References}

1. Lipton RB, Bigal ME, Diamond M, Freitag F, Reed ML, Stewart WF, et al. Migraine prevalence, disease burden, and the need for preventive therapy. Neurology. 2007 Jan;68(5):343-9. https://doi. org/10.1212/01.wnl.0000252808.97649.21

2. Gil-Gouveia R, Oliveira AG, Martins IP. Subjective cognitive symptoms during a migraine attack: a prospective study of a clinic-based sample. Pain Physician. 2016 Jan;19(1):E137-50.

3. Gil-Gouveia R, Martins IP. Clinical description of attack-related cognitive symptoms in migraine: A systematic review. Cephalalgia. 2018 Jun;38(7):1335-1350. https://doi.org/10.1177/0333102417728250

4. Gil-Gouveia R, Martins IP. Cognition and cognitive impairment in migraine. Curr Pain Headache R. 2019;23(11):84. https://doi. org/10.1007/s11916-019-0824-7

5. Schulte LH and May A. The migraine generator revisited: continuous scanning of the migraine cycle over 30 days and three spontaneous attacks. Brain. 2016 Jul;139(Pt 7):1987-93. https://doi.org/10.1093/ brain/aww097

6. Maniyar FH, Sprenger T, Monteith T, Schankin C, Goadsby PJ. Brain activations in the premonitory phase of nitroglycerin-triggered migraine attacks. Brain. 2014 Jan;137(Pt 1):232-41. https://doi. org/10.1093/brain/awt320

7. Giffin NJ, Ruggiero L, Lipton RB, Silberstein SD, Tvedskov JF, Olesen $J$, et al. Premonitory symptoms in migraine: an electronic diary study. Neurology. 2003 Mar;60(6):935-40. https://doi.org/10.1212/01. wnl.0000052998.58526.a9

8. Quintela E, Castillo J, Munoz P, Pascual J. Premonitory and resolution symptoms in migraine: a prospective study in 100 unselected patients. Cephalalgia. 2006 Sep;26(9):1051-60. https://doi. org/10.1111/j.1468-2982.2006.01157.x

9. Palm-Meinders IH, Koppen H, Terwindt GM, Launer LJ, Konishi J, Moonen JM, et al. Structural brain changes in migraine. JAMA. 2012 Nov 14;308(18):1889-97. https://doi.org/10.1001/jama.2012.14276

10. Tolner EA, Chen SP, Eikermann-Haerter K5. Current understanding of cortical structure and function in migraine. Cephalalgia. 2019 Nov;39(13):1683-99. https://doi.org/10.1177/0333102419840643
11. Natoli JL, Manack A, Dean B, Butler Q, Turkel CC, Stovner L, Lipton RB. Global prevalence of chronic migraine: a systematic review. Cephalalgia. 2010 May;30(5):599-609. https://doi.org/10.1111/ j.1468-2982.2009.01941.x

12. Buse DC, Manack AN, Fanning KM, Serrano D, Reed ML, Turkel CC, et al. Chronic migraine prevalence, disability, and sociodemographic factors: results from the American Migraine Prevalence and Prevention Study. Headache. 2012 Nov-Dec;52(10):1456-70. https:// doi.org/10.1111/j.1526-4610.2012.02223.x

13. Calandre EP, Bembibre J, Arnedo ML, Becerra D. Cognitive disturbances and regional cerebral blood flow abnormalities in migraine patients: their relationship with the clinical manifestations of the illness. Cephalalgia. 2002 May;22(4):291-302.https://doi. org/10.1046/j.1468-2982.2002.00370.x

14. Huang L, Juan Dong $H$, Wang $X$, Wang $Y$, Xiao Z. Duration and frequency of migraines affect cognitive function: evidence from neuropsychological tests and event-related potentials. J Headache Pain. 2017 Dec;18(1):54. https://doi.org/10.1186/ s10194-017-0758-6

15. Latysheva NV Filatova E, Osipova D, Danilov AB. Cognitive impairment in chronic migraine: a cross sectional study in a clinic-based sample. Arq Neuro-Psiquiatr. In press.

16. Baars MA, van Boxtel MP, Jolles J. Migraine does not affect cognitive decline: results from the Maastricht aging study. Headache. 2010 Feb;50(2):176-84. https://doi.org/10.1111/j.1526-4610.2009.01572.x

17. Martins IP, Maruta C, Silva C, Rodrigues P, Chester C, Ginó S, et al. The effect of education on age-related changes in three cognitive domains: a cross-sectional study in primary care Appl Neuropsychol Adult. 2012;19(4):287-98. https://doi.org/10.1080/09 084282.2012 .670145

18. Pellegrino-Baena C, Goulart AC, Santos IS, Suemoto CK, Lotufo PA, Bensenor IJ. Migraine and cognitive function: Baseline findings from the Brazilian Longitudinal Study of Adult Health: ELSA-Brasil. Cephalalgia. 2018 Aug;38(9):1525-34. https://doi. org/10.1177/0333102417737784 